\title{
Inisiasi Kemampuan Berwirausaha melalui Pengenalan E-Commerce bagi Anak Panti Asuhan Yatim Muhammadiyah Cabang Blimbing Sukoharjo
}

\author{
Mohtar Yunianto ${ }^{1}$, Budi Purnama², Kusumandari², Utari $^{2}$ \\ 1, 2 Universitas Sebelas Maret
}

\begin{abstract}
Article History ABSTRACT
Received 23.06.2019 Received in revised form 05.09.2019

Accepted 16.09.2019

Available online 28.10.2019

INITIATING ENTREPRENEURIAL SKILLS THROUGH THE INTRODUCTION OF E-COMMERCE FOR ORPHANS OF THE MUHAMMADIYAH ORPHANAGE IN BLIMBING SUKOHARJO. Efforts to improve skills and the cultivation of entrepreneurial spirit have been carried out at the Orphanage PKU Muhammadiyah Cabang Blimbing. This institution is home to 20 orphans located in Wonorejo, Polokarto, Sukoharjo. Wonorejo village is a convection village where most of the population work as convection producers, which in the sale of their clothes still use conventional methods, which are sold in stores and in markets. The pattern of mutually beneficial cooperation between convection entrepreneurs and orphans is initiated by technopreneurship activities namely by selling convection through online stores.

KEYWORDS: Benefical Cooperation, E-Commerce, Entrepreneurship, Online Stores.
\end{abstract}

DOI: $10.30653 / 002.201943 .155$

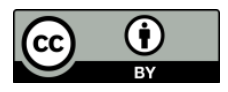

This is an open access article distributed under the terms of the Creative Commons Attribution 4.0 International License, which permits unrestricted use, distribution, and reproduction in any medium, provided the original work is properly cited. ๑) 2019 Mohtar Yunianto, Budi Purnama, Kusumandari, Utari.

\section{PENDAHULUAN}

Kondisi pertumbuhan jumlah penduduk Indonesia yang sangat pesat akan sangat berpengaruh dalam bidang perekonomian negara, terutama dalam hal lapangan perkerjaan, dalam hal peningkatan perekonomian masyarakat pemerintah berupaya mendorong masyarakat untuk berwirausaha. Hal yang sangat penting dalam berwirausaha adalah partisipasi masyarakat yang akan memberikan pondasi yang kokoh untuk sistem ekonomi dan bisnis di negara Indonesia, semakin banyak masrayakat yang membuka lahan wirausaha makan berarti akan membuka lapangan kerja baru dan mengurangi angka kemiskinan. Pada tahun 2018 rasio kewirausahaan di Indonesia meningkat menjadi $7 \%$ dari total penduduk Indonesia. Sebelumnya, pada 2014, rasio wirausaha di Tanah Air baru 1,55\%, kemudian meningkat menjadi 1,65\% di 2016, dan

${ }^{1}$ Corresponding author: Program Studi Fisika FMIPA Universitas Sebelas Maret Surakarta; Jl. Ir. Sutami 36 A Kentingan Surakarta; Email: mohtaryunianto@staff.uns.ac.id 
bergerak ke 3,1\% pada akhir 2017 (Prasetya, 2018). Rasio ini memberikan harapan sangat baik dalam pembangunan sosial ekonomi bangsa, karena tingkat ketergantungan terhadap pemerintah dalam penyediaan lapangan kerja semakin berkurang (Firdaus, 2018).

Dalam hal perkembangan teknologi informasi saat ini selaras dengan laju pertumbuhan penuduk Indonesia, dimana perubahan teknologi yang sangat cepat sehingga dalam berbisnis penggunaan teknologi tersebut menjadi persyaratan penting (Irmawati, 2011). Oleh karena itu terkait dengan perilaku berwirausaha maka pelaku wirausaha terutama dari usia dini maupun usia produktif yang seharusnya memiliki bekal ilmu berwirausaha yang lebih baik dengan memanfaatkan teknologi informasi melaui bisnis online (Nugraha \& Wahyuhastuti, 2017; Nuhafizah, 2018).

PKU Muhammadiyah Cabang Blimbing merupakan bagian dari Muhammadiyah cabang yang berada dalam wilayah cakupan kecamatan polokarto Kabupaten Sukoharjo. Berdirinya PKU Muhammadiyah bersamaan dengan berdirinya Muhammadiyah Cabang Blimbing tanggal 23 November 1928. PKU melakukan kegiatan kemanusiaan yang bersifat insidental dan belum dilaksanakan secara rutin, mengingat kemampuan PKU yang masih terbatas. Kegiatan yang dilakukan saat itu adalah menolong orang kesusahan, membantu orang sakit dengan menghimpun dana dari para anggota masyarakat. Tahun 1979 mulai meningkatkan kegiatan dengan mengadakan khitanan massal tanpa dipungut biaya. Setiap anak yang dikhitan diberikan pakaian dan sarung secara gratis. Pada tahun 1982 dibangunlah sebuah gedung yang selanjutnya digunakan sebagai kantor PKU di atas tanah waqof Bapak H. Sayuti.

Panti Asuhan Yatim PKU Muhammadiyah Cabang Blimbing adalah menyantuni anak Yatim, Piatu, yatim piatu, fuqara' wal masakin, untuk dibantu biaya pendidikannya mulai tingkat SD/MI sampai SLTA. Anak-anak diasuh didalam Panti. Selama di dalam panti asuhan anak-anak juga mendapatkan pembinaan tentang keislaman dan kemuhammadiyahan serta bekal keterampilan sehingga selepas dari Panti diharapkan mereka dapat menjadi insan yang mandiri dan berakhlak mulia. Bentuk asuhan ada dua yaitu yang diasramakan sejumlah 20 anak dan yang tidak diasramakan sejumlah 44 anak. Pemilihan asrama atau tidak tersebut berdasarkan pertimbangan efektifitas dan efisiensi oleh para pengurus.

Desa Wonorejo yang merupakan desa dimana asrama tersebut berada di sebut Desa sentra Konveksi, karena ada 200an Kepala keluarga di desa Wonorejo berprofesi sebagai pengusaha konveksi, berbagai hasil produk konveksi dari seragam sekolah, baju harian, baju anak-anak, batik dan juga baju sekelas butik, selama ini proses penjualan menggunakan cara konvensional yaitu dengan menjual ke pasar di eks karesidenan Surakarta maupun di jual di toko pribadi dimana show room nya berada di pinggir jalan utama desa wonorejo.

Bekal ketrampilan yang diberikan pada anak asuh selama ini masih sebatas ketrampilan formal yang tidak mengarah ke bentuk wirausaha yang memberikan profit, bertolak dari keberadaan asrama yang berada di desa Konveksi serta kemampuan anak yang seusia SMP dan SMA maka koordinasi dan kerjasama antara pihak asrama dan pihak pengusaha konveksi sangat tepat untuk proses pemasaran secara online, dengan memberikan pelatihan kepada anak-anak asuh asrama untuk ikut menjualkan melalui 
online marketing sekaligus memupuk jiwa wirausaha yang menjadi tambahan keahlian saat nanti sudah tidak di asrama lagi.

Berdasar dari pendahuluan tersebut dalam artikel ini disajikan adanya kegiatan yang saling memberi kemanfaatan antara anak yatim yang berada di Panti Asuhan Yatim serta para produsen konveksi, dimana melalui Upaya peningkatan kemampuan berwirausaha melalui Teknologi Informasi dimana secara umum anak yatim di ajari membuat toko online dengan barang-barang yang dijual dalam toko online tersebut merupakan barang produksi dari pemilik konveksi.

\section{METODE PELAKSANAAN}

Kegiatan pengabdian yang dilakukan dalam rangka peningkatan pemampuan berwirausaha bagai anak asuh yatim di PKU Muhammadiyah Cabang Blimbing dilakukan dalam beberapa tahapan, adapun metode pengabdian yang dilakukan sebagai berikut :

1) Koordinasi yang baik antara pihak Panti Asuhan dan juga ke pihak pengusaha konveksi terkait dengan rencana kegiatan peningkatan kemampuan wirausaha dengan mengunjungi Panti Asuhan dan beberapa pengusaha konveksi.

2) Pemasangan jaringan koneksi internet di asrama untuk proses pelatihan dan implementasi serta keberlanjutan kegiatan.

3) Pelaksanaan pelatihan secara intensif bagi anak-anak penghuni Asrama panti berkaitan dengan pemanfaatan teknologi informasi untuk online marketing kerjasama dengan para pengusaha konveksi di sekitar asrama, dimana langkah teknisnya adalah pemanfaatan online marketing yaitu tokopedia, lazada, shoope atau olx untuk membuat akun toko online yang digunakan untuk mengiklankan produk konveksi dengan teknik pemasaran-pemasaran dan strategi yang yang baik dan tepat.

4) Pelaksanaan pelatihan proses editing gambar dan tata bahasa yang layak untuk di upload di online marketing sekaligus strategi dalam pemasaran secara online.

5) Pelaksanaan pelatihan pemilihan produk-produk yang layak diunggah di toko online bekerjasama dengan pengusaha konveksi di desa Wonorejo.

6) Melaksanaan pendampingan sampai bisa secara mandiri, pendampingan dilakukan setiap 3 minggu sekali sampai yang dilatih benar-benar dapat mengaplikasikan ilmu hasil pelatihan dengan baik dan mandiri.

7) Monitoring dan evaluasi berdasarkan dari target pelaksanaan kegiatan.

\section{HASIL DAN PEMBAHASAN}

Kegiatan peningkatan kemampuan berwirausaha berbasis Teknologi informasi telah dilakukan, tahap awal yang dilakukan adalah berkoordinasi dengan pihak PKU Muhammadiyah sebagai pengelola panti asuhan tersebut, dari pihak pengelola memberikan kemudahan akses bagi kegiatan ini dengan memberikan jadwal kegiatan setiap hari minggu sore, sedangkan koordinasi lain dilakukan dengan pihak produsen konveksi, ada 3 produsen konveksi yang bekerjasama dengan pihak pelaksanaan yaitu fanesa konveksi, Juan konveksi dan Empat Sekawan konveksi. Ketiga konveksi tersebut 
memproduksi aneka bentuk konveksi, diantaranya adalah gamis, jilbab, baju wanita, baju anak-anak serta baju seragam kebutuhan sekolah. Ketiganya menyatakan bersedia dalam menyediakan akses ke produk-produknya untuk di onlinekan serta menyediakan informasi-informasi yang diperlukan lainnya.

Pemasangan internet di panti asuhan juga dilakukan dalam upaya penyediaan koneksi internet bagi anak panti, dimana kegiatan pembuatan toko online serta proses upload barang-barang yang akan di onlinekan sangat memerlukan koneksi internet yang memadai. Tahap awal adalah memberikan pemahaman berkaitan dengan dasar-dasar kewirausahaan serta pengenalan teknologi informasi, agar diperoleh pemahaman yang sama karena anak asuh yang dilatih memiliki tingkat pendidikan yang berbeda-beda dari usia SD sampai usia SMA. Setelah internet terpasang dengan baik langkah selanjutnya adalah pelatihan pembuatan toko online sebagai tersaji pada Gambar 1, permasalahan yang mendasar adalah handphone atau telepon gengam yang dimiliki memiliki performa yang tidak maksimal sehingga banyak dari peserta yang tidak dapat menginstal aplikasi baik tokopedia, bukalapak, shoope karena keterbatasan memory internal dari handphone yang digunakan, solusinya adalah membuat toko menggunakan browser dari handphone, kendala yang dihadapi apabila menggunakan browser dari handphone adalah toko online tidak selalu aktif karena harus login untuk mengakses toko onlinenya, tidak seperti halnya menginstal aplikasi melalui playstore yang akan selalu aktif, sehingga jika ada notifikasi missal ada pesanan, ada pertanyaan akan muncul di aplikasi tersebut ke user.

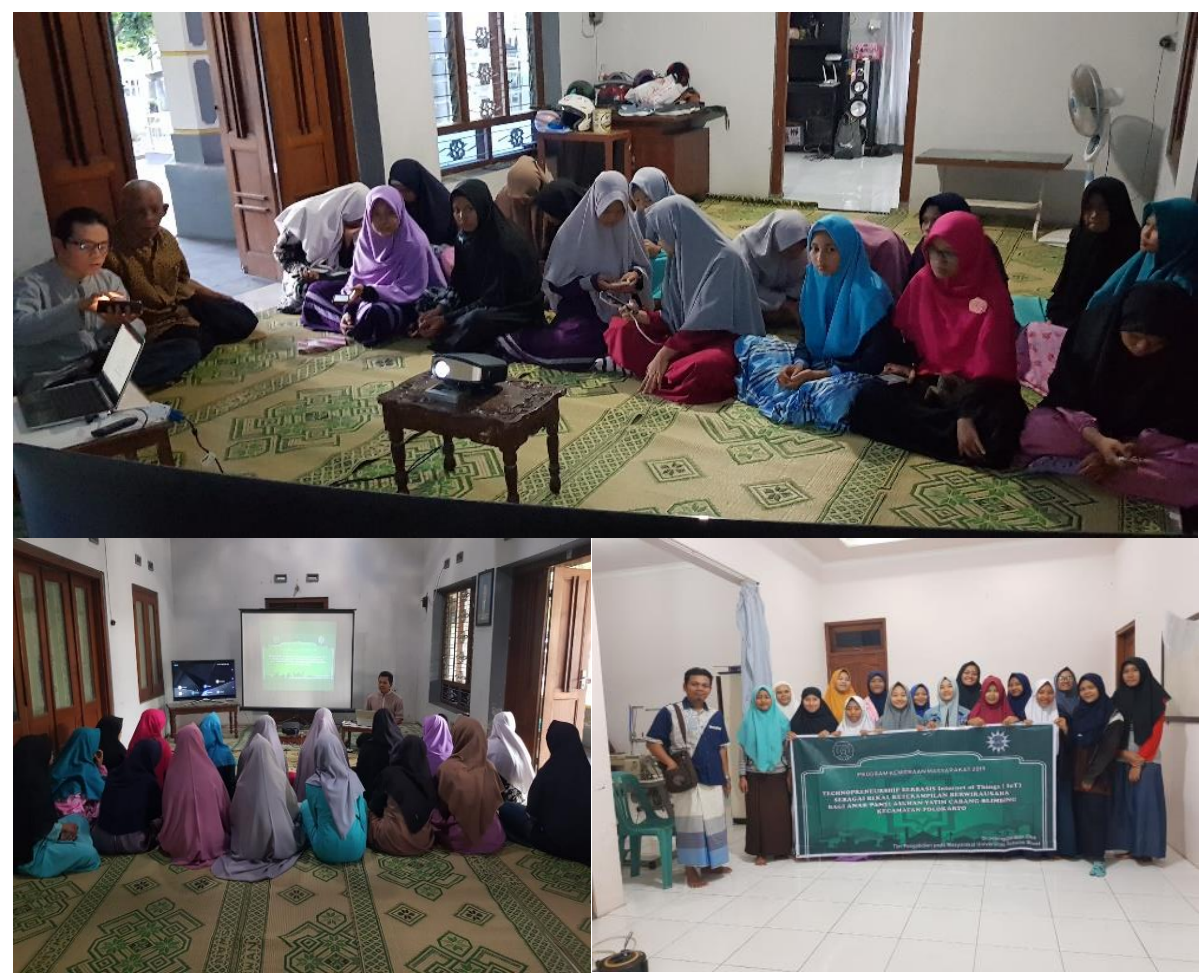

Gambar 1. Searah Jarum Jam: (a) Pelaksanaan Pelatihan Pembuatan Toko Online dari Proses, (b) Para Peserta Pelatihan, dan (c) Penjelasan Mengenai Enterpreneurship Berbasis IT

Tahapan selanjutnya yang dilaksanakan adalah pelatihan untuk mengupload produk-produk serta bagaimana cara menyusun tampilan yang menarik pada toko online agar menarik pembeli untuk memberi produknya dan kiat-kiat untuk mengetahui produk 
terlaris yaitu produk di toko online yang terjual paling banyak dan produk yang paling diminati yaitu produk yang sering masuk dalam wishlist pembeli, dimana strategi yang diajarkan adalah melakukan penelusuran dari toko-toko online yang menjual produk serupa dan fokus pada produk-produk tersebut dalam hal ini adalah konveksi. Strategi yang dilakukan adalah memperbanyak jumlah produk atau lebih sering mempromosikan produk tersebut, dengan demikian maka hal ini akan menarik konsumen tertarik membeli produknya (Wicaksono \& Aminata, 2018).

Kegiatan ini berlanjut dengan pendampingan intensif baik dari pihak pengabdi maupun dari pihak pemilik konveksi. Kegiatan ini akan terlihat hasilnya setelah minimal 3-6 bulan sejak toko tersebut dibuat dikarenakan usaha toko online membutuhkan waktu lama untuk promosi, kefokusan, keseriusan untuk mendapatkan kepercayaan dari pembeli, karena dalam sebuah jualan online kepercayaan sangat penting hal ini diindikasi dengan adanya tanda power Badge. Power Badge merupakan logo hijau berbentuk mahkota yang akan muncul pada produk dan toko online yang dibuat (Rahman dan Mawardi, 2017). Manfaat power Badge ini adalah dapat mengikuti promo spesial, menunjukkan keseriusan penjual dan lebih menarik perhatian pembeli. Adapun strategi dalam memperoleh Power Badge jika memenuhi kriteria adalah dengan berlangganan Power Merchant, meningkatkan skor performa toko hingga 75 dengan melakukan beberapa tips sebagai berikut:

1) Mengirim barang segera setelah pesanan masuk.

2) Membalas Chat dari pembeli dengan cepat dan tidak membiarkan chat dari pembeli tidak terbalas.

3) Melakukan verifikasi toko dengan mengupload foto diri dan focopy KTP.

4) Menghindari poin pinalty toko dengan memberikan pelayanan terbaik kepada pembeli.

Manfaat yang dapat diperoleh oleh mitra pertama dalam hal ini adalah anak yatim adalah dapat memberikan pengetahuan yang baru berkaitan dengan pemanfaatan IT dalam berwirausaha, dapat menjadi aternatif kegiatan diwaktu senggang serta dampak utama yang diharapkan kedepan selain memberikan ilmu yang positif bagi anak yatim, setelah keluar dari panti asuhan (dalam hal ini setelah luus sekolah tingkat SMA) dapat lebih mengembangkan sehingga dapat memberikan hasil secara nasional, sedangkan manfaat yang diperoleh mitra kedua yaitu pemilik konveksi di sekitra asrama yatem tersebut adalah memberikan alternatif dalam penjualan produknya, yang semula berbasis offline dengan di jual ke toko dan pasar maka ada alternatif lain berupa penjuaan secara online, tidak perlunya menambah karyawan untuk proses penjualan akan tetapi dengan memaksimalkan kemampuan dari anak yatim sehingga dampaknya adalah penjualan dari produk konvensi tersebut akan mengalami kenaikan sehingga omsetnya juga akan bertambah.

\section{SIMPULAN}

Kegiatan pengabdian pada masyarakat yang telah dilakukan adalah berupa inisiasi pengembangan kewirausahaan bagi anak-anak panti asuhan yatim Muhammadiyah Cabang Blimbing melalui pembuatan toko online bekerjasama dengan pengusaha konveksi di sekitar Panti Asuhan tersebut, kegiatan awal telah dilaksanakan dengan 
memberikan pemahaman berkaitan dengan berwirausaha secara online, baik aspek risiko maupun manfaatnya, telah dapat membuat toko online dan strategi-strategi agar toko online yang dibuat dapat terjual produknya baik dalam jumlah maupun kecepatan penjualan, kegiatan ini akan terus dilaksanakan untuk melakukan pendampingan agar saling memberi manfaat antara anak yatim dengan pemilik konveksi.

\section{REFERENSI}

Firdaus, N. (2018). Pengentasan kemiskinan melalui pendekatan kewirausahaan sosial. Jurnal Ekonomi dan Pembangunan, 22(1), 55-67.

Irmawati, D. (2011). Pemanfaatan e-commerce dalam dunia bisnis. Jurnal Ilmiah Orasi Bisnis, 6, 95-112.

Nugraha, A. E. P., \& Wahyuhastuti, N. (2017). Start up digital business: sebagai solusi penggerak wirausaha muda. Jurnal Nusantara Aplikasi Manajemen Bisnis, 2(1), 1-9.

Nurhafizah, N. (2018). Bimbingan awal kewirausahaan pada anak usia dini. Jurnal Konseling dan Pendidikan, 6(2), 62-67.

Prasetyo, A. (2018). Rasio Wirausaha Indonesia Sentuh 7\%, Retrieved June 12, 2019 from https://mediaindonesia.com/read/detail/164639-rasio-wirausaha-indonesia-sentuh-7

Rahman, F., \& Mawardi, M. K. (2017). Strategi UMKM dalam membangun brand toko online di marketplace (Studi pada komunitas tokopedia di Kota Bekasi). Jurnal Administrasi Bisnis, 53(1), 39-48.

Wicaksono, S. A., \& Aminata, J. (2018). Analisis faktor-faktor yang mempengaruhi pendapatan umkm pada marketplace online tokopedia, bukalapak, dan shopee. Semarang: Fakultas Ekonomika dan Bisnis. 